\title{
Commentary Sedation practice: is it time to wake up and embrace change?
} Kate Regan and Owen Boyd

\author{
Intensive Care Unit, Royal Sussex County Hospital, Eastern Road, Brighton, BN2 5BE, UK
}

Corresponding author: Owen Boyd, owen.boyd@bsuh.nhs.uk

Published: 8 January 2008

Critical Care 2008, 12:102 (doi:10.1186/cc6203)

This article is online at http://ccforum.com/content/12/1/102

(C) 2008 BioMed Central Ltd

See related research by Martin et al., http://ccforum.com/content/11/6/R124

\begin{abstract}
Recommendations for sedation regimes in the intensive care unit (ICU) have evolved over the last decade based on findings that relate the clinical approach to improved patient outcomes. Martin and co-workers conducted two surveys into German sedation practice covering the time period during which these changes occurred and as such provide an insight into how these recommendations are being incorporated into everyday clinical practice.
\end{abstract}

In the previous issue of Critical Care, Martin and co-workers, [1] report the results of a survey examining changes in sedation management in German intensive care units (ICUs). This review of 214 ICUs is made more informative by their use of the same questionnaire used by this group in 2002, allowing changes in practice to be evaluated.

The recommended targets of sedation within the ICU have evolved over recent years, led by a number of consensus statements. Patients that used to be heavily sedated, to keep them compliant for invasive procedures, are now easily roused for assessment, communication and reassurance. Drug regimes have changed from being "carer-orientated" continuous infusions, to "patient-orientated" regimes targeted around sedation scales. Furthermore daily interruptions in infusions avoid the build up of sedative drugs in the changing pharmacological environment of the ICU patient. Both of these strategies have been shown to reduce duration of mechanical ventilation and ICU stay [2,3]. The survey of Martin et al. reports the impact of these changes to the clinical practice of sedation in the German ICUs between 2002 and 2006, at a time when these international trends were being developed. They show that $51 \%$ of units are now using a sedation scale compared to $8 \%$ in 2002 . Sedation protocols are used in $46 \%$ of ICUs, compared with $21 \%$ in 2002 , and $34 \%$ have introduced daily sedation holds. This is significant change, but the survey shows how it clearly takes time for the impact of clinical research to be incorporated into everyday practice. This is despite strong endorsements for the use of sedation scales, patient-targeted sedation and daily sedation holds from the Society for Critical Care Medicine (SCCM) guidelines for sedation [4], the Surviving Sepsis Campaign guidelines [5] for the management of severe sepsis and the National Institute for Health ventilator care bundles.

The current survey also allows us to look at the changes in the use of different sedative agents. In the ICUs that responded to the survey, broadly, there is a trend away from a hypnosis-based approach with benzodiazepines, and towards a more analgesia-based approach. However the ideal sedative agent has yet to be developed, and despite the plethora of recommendations on sedative practice in the above publications, there are no high-quality, large-scale, randomised controlled trials of different sedative agents in the ICU $[4,6]$. This lack of guidance is apparent in the large number of agents reportedly used by respondents in the current survey. The increased use of short-acting opioids and regional analgesia with epidural and peripheral nerve blocks suggests a greater focus on analgesia within the ICU. This is backed up by evidence that effective treatment of pain in the ICU can lead to a reduction in the duration of mechanical ventilation when used in conjunction with pain scores against which to titrate analgesia [7]. In the current survey only $21 \%$ of units have introduced pain scores, again, despite the endorsement of such scores - in particular, the numerical rating score - by the SCCM sedation guidelines [4].

The purpose of national guidelines and consensus statements is to aid the development of local protocols. Perhaps this survey suggests there remains resistance amongst clinicians to the adoption and use of such protocols, perhaps because it may remove their autonomy and override clinical judgement. A protocol itself does not guarantee improvement in outcomes, however it remains a tool with which to direct 
care, and review practice [8]. Managing change within the ICU is not an area that most physicians have formal training in, and it is often a difficult managerial task. Chan and coworkers report their success using a multi-disciplinary task force to develop and implement change in the area of weaning protocols [9]. The shared ownership of the protocols may have provided motivational support and improved compliance.

Surveys are a common tool used to investigate practice in many areas of clinical work. However they rely on retrospective data collection and it is frequently unclear how the data quality is controlled, which patient types are discussed or how the source of data collection compares to our own patient population. Is the respondent replying in the context of actual clinical practice on the ground, or of a protocol, never actually employed?

On the positive side, surveys can be used to provide information with which practitioners can compare their own practice to others and gain confidence that they are with the mainstream. In addition they may be used to aid the setting of local standards and commissioning of further services. However they may not help us with more basic clinical questions about improving outcomes, which can only be addressed by randomised clinical trials. In this setting, the current survey is detailed, but how will it change clinical practice for the better?

\section{Competing interests}

The authors declare that they have no competing interests.

\section{References}

1. Martin J, Franck M, Sigel S, Weiss M, Spies CD: Changes in sedation management in German intensive care units between 2002 and 2006: a national follow up survey. Crit Care 2007, 11:R124.

2. Brattebø G, Hofoss D, Flaatten H, Muri AK, Gjerde S, Plsek PE: Effect of a scoring system and protocol for sedation on duration of patients' need for ventilator support in a surgical intensive care unit. BMJ 2002, 324:1386-1389.

3. Kress JP, Pohlman AS, O'Connor MF, Hall JB: Daily interruption of sedative infusions in critically ill patients undergoing mechanical ventilation. $N$ Engl J Med 2000, 342:1471-1477.

4. Jacobi J, Fraser GL, Coursin DB, Riker RR, Fontaine D, Wittbrodt ET, Chalfin DB, Masica MF, Bjerke HS, Coplin WM, et al.; Task Force of the American College of Critical Care Medicine (ACCM) of the Society of Critical Care Medicine (SCCM), American Society of Health-System Pharmacists (ASHP), American College of Chest Physicians: Clinical practice guidelines for the sustained use of sedatives and analgesics in the critically ill adult. Crit Care Med 2002, 30:119-141.

5. Dellinger RP, Carlet JM, Masur H, Gerlach H, Calandra T, Cohen J, Gea-Banacloche J, Keh D, Marshall JC, Parker MM, et al.; Surviving Sepsis Campaign Management Guidelines Committee: Surviving Sepsis Campaign guidelines for management of severe sepsis and septic shock. Crit Care Med 2004, 32:858873.

6. Ostermann ME, Keenan SP, Seiferling RA, Sibbald WJ: Sedation in the intensive care unit: a systematic review. JAMA 2000, 283:1451-1459.

7. Chanques G, Jaber S, Barbotte E, Violet S, Sebbane M, Perrigault PF, Mann C, Lefrant JY, Eledjam JJ: Impact of systematic evaluation of pain and agitation in an intensive care unit. Crit Care Med 2006, 34:1691-1699.
8. Wall RJ, Dittus RS and Ely EW: Protocol-driven care in the intensive care unit: a tool for quality. Crit Care 2001, 5:283285.

9. Chan PK, Fischer S, Stewart TE, Hallett DC, Hynes-Gay P, Lapinsky SE, MacDonald R, Mehta S: Practising evidence-based medicine: the design and implementation of a multidisciplinary team-driven extubation protocol. Crit Care 2001, 5:349354. 